\title{
SISTEMATIZAÇÃO: PROBLEMA CENTRAL DA CIÊNCIA JURÍDICA
}

\author{
SYSTEMATIZATION: CENTRAL PROBLEM OF LEGAL SCIENCE
}

Maria Helena Diniz

Livre-Docente pela Pontifícia Universidade católica de São Paulo - PUCSP. Professora Titular de Direito Civil da Pontifícia Universidade católica de São Paulo -

PUCSP.

Convidada

Doi: $10.5585 /$ rdb.v13i6.368

RESUMO: Assinala este breve trabalho alguns pontos altos, mais expressivos para a configuração do papel da ciência do direito na construção do sistema jurídico, buscando demonstrar que a sistematização seria o problema fundamental do jurista, tornando possível apontar critérios conducentes à solução das questões hermenêuticas engendradas pela aplicação do direito.

Palavras-chave: Ciência jurídica; Linguagem do jurista; Sistema; Metodologia; Aplicação do direito.

ABSTRACT: The present brief work points some highlights, more significant for configuration of the role of the science of law in the construction of the legal system, looking for showing that the systematization would be the fundamental problem of the jurist, making it possible to identify criteria leading to the solution of hermeneutical issues engendered by the application of the law.

Keywords: science of law; Language of the jurist; System; Methodology; Application of the Law.

Antes de analisarmos o papel da ciência jurídica, urge respondermos à indagação: o que é ciência?

Ciência indica conhecimento, por razão etimológica, pois deriva do latim scientia, oriundo de scire, ou seja, saber. Seria um complexo de conhecimentos ordenados e conexos entre si. Se assim é, o conhecimento científico é o que procura dar às suas constatações um caráter descritivo, genérico, comprovado e sistematizado. Constitui, um corpo sistemático de enunciados verdadeiros. Em suma, ciência é um saber metodicamente fundado, demonstrado $e$ sistematizado. A sistematicidade é o principal argumento para afirmar a cientificidade. ${ }^{1} \mathrm{Da}$ sistematização decorre, portanto, a justificação do saber científico. Para que haja ciência, deve haver as seguintes notas: caráter metódico, sistemático, certo, fundamentado, condicionado a

\footnotetext{
${ }^{1}$ Alves da Silva, Introdução à ciência do direito, São Paulo, Salesianas, 1940, p. 5; Tércio Sampaio Ferraz Jr., A ciência do direito, São Paulo, Atlas, 1977, p. 10 e 11; Direito, retórica e comunicação, São Paulo, Saraiva, 1973, p. 160 e 161.
}

Revista de Direito Brasileira | São Paulo, SP | v. 13 | n. 6 | p. 88 - 94| jan./abr. 2016 
um objeto, que é a coisa descircunstancializada pela atividade teorética ${ }^{2}$. O objeto é aquele a que a ciência tende ou que ela conhece, mediante uso de um método.

Se assim é qual seria, então, o objeto em torno do qual o jurista desenvolve seu estudo?

A ciência do direito, como toda ciência, tem um objeto, que é o direito, apesar de, devido a sua pluridimensionalidade, conter inúmeros elementos heterogêneos que dificultam uma abordagem unitária, o estuda ora sob um aspecto ora sob outro, conforme a mundividência ou posição jusfilosófica do jurista.

O único objeto da ciência jurídica seria o conhecimento do direito, que traz grande complexidade, por isso, para delimitar o ângulo de sua análise, deverá antes seguir uma corrente jusfilosófica indicativa dos elementos do objeto direito, que deverão ser estudados pelo jurista. ${ }^{3}$ É, portanto, o critério filosófico adotado pelo jurista que determinará seu objeto. Essa operação pela qual se constitui o objeto é governada pelo método, que fixará as bases da sistematização da ciência jurídica. O sucesso da investigação científica depende do método adotado, que dê coerência e sentido à operatividade científica.

A preocupação científica é atingir a verdade por via metódica, mediante enunciados lógico-descritivos, que propõem critérios para transmitir uma informação precisa sobre a realidade a que se referem. ${ }^{4}$

A ciência jurídica é um conhecimento sistemático, metodicamente obtido e demonstrado, dirigido a um ou mais elementos do direito.

O principal escopo da ciência do direito é a sistematização jurídica, tendo uma função organizatória, por criar condições para classificação, tipificação e sistematização dos fatos relevantes. Como a norma constitui o núcleo teórico, o jurista procura solucionar problemas ligados à hermenêutica, às fontes do direito, ao sujeito do direito, ao direito subjetivo e a relação jurídica. A solução desses problemas levou a ciência jurídica a ser uma espécie analítica das figuras jurídicas, que teria por finalidade última encadeá-las num sistema, constituindo um saber sistemático capaz de dar um quadro coerente do direito como conexão de normas e dos elementos que o compõem.

A ciência do direito, então, preocupa-se, com as questões: a) da procura da norma vigente; b) da validade Constitucional, formal, fática, ideal e ética, procurando averiguar: se a norma, que descreve, é conforme ao comando constitucional (validade constitucional); se foi elaborada pelo órgão competente em obediência aos procedimentos legais (validade formal); se ela é efetiva, ou seja, quando ocorrem o comportamento que ela configura (hipótese de incidência) e a consequência jurídica (sanção) que ela prevê (validade fática); se ela se impõe para a solução de um conflito de interesses, em virtude de uma proposta de um autornos quadros argumentativos de uma doutrina, preocupando-se com a legitimidade do direito, por ter relevância doutrinária (validade ideal); se há fundamento axiológico do direito (validade ética); c) da estrutura hipotética da norma, averiguando se: teria ela a estrutura de um juízo hipotético condicional, disjuntivo, conjuntivo ou adversativo; ou se a sanção seria parte essencial da estrutura lógico-normativa, envolvendo o problema de conexão de normas, já que há normas que não a preveem; d) da sistematização jurídica ou da unidade sistemática do direito, que é sua principal tarefa.

\footnotetext{
2 José M. Vilanova, Filosofia del derecho y fenomenologia existencial, Buenos Aires, Cooperadora de Derecho y Ciencias Sociáles, 1973, p. 22, 86 e 100; Gilles, Pensée formelle et sciences de l'homme (prefacio), 1967.

3 Júlios Luis Moreno, Los supuestos felosó fechos de la ciencia jurídica, Montevideo, 1963, p. 54; Carlos Mouchet e Ricardo Z. Becu, Introducción al derecho, Buenos aires, Abelado-Perrot, 1970, p. 75.

${ }^{4}$ José Salgado Martins, O método no direito, Revista da Faculdade de Porto Alegre, 1:903 e s, 1951, ano 3; Tércio Sampaio Ferraz Jr., A ciência do direito, cit. p. 42 e 43.
} 
Mas o que seria sistema? O vocábulo sistema é de origem grega, significando aquilo que é construído (syn-istemi), isto é, uma totalidade, cujas partes, na sua articulação, apontam para uma ordem. Platão, Aristóteles e os estóicos empregaram-no, os primeiros no sentido de algo organizado e os segundos para designar ação tecnicamente planejada e racional. Os romanos não utilizaram o termo. A palavras só surgiu por volta dos séculos XVI e XVII com a teoria da musica e com a teologia, impondo-se no século XVIII, com o jusnaturalismo, e na ciência em geral, pois Christian Wolff falava em sistema como nexus veritatum, apoiando-se na correção formal e na perfeição da dedução. Lambert, nos Fragmentos de sistemalogia, estabelecia o sistema como um conceito geral e abstrato, em que o todo é a soma das partes e em si mesmo fechado, onde as suas relações com às partes e as relações das partes entre si estavam determinadas por regras próprias. Sendo que, para Kant, esse todo não seria a soma das partes, mas as precede de algum modo, não permitindo composição e decomposição sem a perda da unidade central, distinguindo o sistema da mera agregação. Hegel e Eisler empregam o vocábulo "objetivamente" como interdependência totalizante e ordenada de partes, onde a determinação das partes pelo todo ou do todo pelas partes varia de concepção para concepção, e "logicamente", como ordenação de uma pluralidade de conhecimentos numa totalidade do saber, aproximando, assim, o termo "sistema" à ideia de "método", sendo que até hoje a palavra "sistemático" é tomada muitas vezes no sentido de "metódico". Heck liga o sistema à noção de ordem. A palavra "sistema" toma conta da terminologia cientifica no século XVIII e passa para o XXI.

Fácil é perceber que "sistema" é um todo organizado racionalmente e planejado metodicamente, portanto significa nexo, uma reunião de elementos, e método, um instrumento de análise. A sistematização é uma operação logica que estabelece um nexo entre os elementos do direito, que constituem o objeto da análise do jurista, para dar uma unidade. De modo que o sistema não é uma realidade, é o aparelho teórico, mediante o qual se pode estudá-la. É, por outras palavras, o modo de ver ou de ordenar, logicamente, a realidade, que não é sistemática. Todo o sistema é uma reunião de objetos de seu estudo e seus atributos ou elementos (repertório) relacionados entre si, conforme certas regras (estrutura) que variam de concepção para concepção (p. ex. para Kelsen o repertório seria a norma, e a estrutura, a regra de infra-supra ordenação, visto que a norma inferior retira a sua validade da norma superior, dando origem ao sistema piramidal. Os adeptos de Kelson constroem, portanto, um sistema de estrutura piramidal, por vislumbrarem uma hierarquia entre as normas, visto que estas se ligam por regras infra-supra ordenação, pois as normas inferiores retiram sua validade das superiores, que dão competência a alguém para positivá-las e indicam o processo de elaboração dessas normas). A descrição do sistema envolve uma opção justilosófica. O que dá coesão ao sistema é sua estrutura. Esse sistema será fechado quando a introdução de um novo elemento o obrigar a mudar as regras, ou seja, a estrutura, e a elaborar, uma nova regra: P. ex. o jogo de xadrez é um sistema fechado, por que se inventarmos uma peça nova ao lado do cavalo, um burro, exemplificadamente, teremos que criar uma regra nova que diga como é que o burro anda: de costas, ou se pode pular como o cavalo etc...O sistema fechado é completo porque contêm uma norma que regula todos os casos e retrospectivo, uma vez que se refere a fatos que circunscreveu. Será aberto quando se pode encaixar um elemento estranho sem necessidade de modificar a sua estrutura, p. ex, poder-se-ia citar a língua portuguesa, na qual podemos utilizar uma palavra pertencente ao repertório de outro sistema sem alterar a estrutura gramatical, dentro de um certo limite, como na frase: "Leasing é uma modalidade contratual”. Porém, se empregassem quatro vocábulos ingleses e um português, haveria quebra da estrutura do sistema linguístico português. Isto porque há um certo limite

\footnotetext{
${ }^{5}$ É a lição de Tércio Sampaio Ferraz Jr; Função social da dogmática jurídica, São Paulo, Revista dos Tribunais, 1978, p. 90, 119 a 140; Direito, retórica e comunicação, cit. p. 95 a 99, 133 a 137; Sistema jurídico e teoria geral dos sistemas, apostila do Curso de Extensão universitária em direito, promovido pela Associação dos Advogados de São Paulo, março a junho de 1973, p. 3, 4, 10 e 11.
} 
para a abertura do sistema. O sistema aberto é incompleto e prospectivo, porque se abre para o que vem, não alterando suas regras. ${ }^{6}$

A função do jurista não é mera transcrição dos elementos do direito, pois, estes não se agrupam em uma ordem, em um todo ordenado, mas sim, na descrição delas, mediante operação lógica que busca estabelecer um nexo entre as normas e outros elementos, dandolhes, uma certa unidade de sentido. A ciência do direito não apenas enumera os elementos que formam o direito, pois o problema fundamental é saber como se articulam entre si esses elementos, qual a raiz de sua validade e qual o critério a adotar para se lhes definir unidade sistemática.

O sistema jurídico é um sistema diferenciado e autônomo, pois controla o que é jurídico e o que não é, isto é, regula o que deve entrar e o que deve sair.

O direito não é um sistema, mas uma realidade que, pode ser estudada sistematicamente. O sistema jurídico é o resultado de uma atividade instauradora que congrega os elementos do direito (repertório) especificados por seus atributos (validade e eficácia), estabelecendo relações entre eles (estrutura), albergando uma referência à mundividência que animou o elaborador desse sistema, projetando-se numa dimensão significativa. $^{7}$

O agrupamento sistemático dos elementos do direito, de forma coerente é tarefa básica do jurista. Por isso se pode afirmar que o direito não é um sistema jurídico, mas uma realidade que pode ser analisada de modo sistemático pela ciência do direito.

É indubitável que a tarefa mais importante do jurista consiste em apresentar o direito sob uma forma ordenada ou sistemática, por meio da qual se tende a facilitar seu conhecimento, bem como seu manejo por parte dos indivíduos que estão submetidos a ele, especialmente pelos que o aplicam. O cientista do direito está dotado de condições que o qualificam como perito, dai possuir uma linguagem técnica, visto que o pensamento cientifico-jurídico é tecnológico. A ciência do direito está ligada à técnica, por ser um conhecimento com domínio de meios para chegar a um fim, por usar de vocabulário especifico, por formular definições e por usar, corretamente as técnicas interpretativas, integrativas e corretivas. O discurso do jurista deve ser racional, provando o que diz com base em lei, jurisprudência e doutrina.

A ciência jurídica exprime-se numa linguagem jurídico-técnica (metalinguagem), que se dirige ao direito (linguagem-objeto) pela qual fixa e comunica o conhecimento. As proposições ou enunciados lógicos do jurista são descritivas e não podem apresentar contradições. Os functores das proposições descritivas são operadores veritativos, daí poderem ser, empiricamente, verdadeiras ou falsas. Os enunciados do jurista teriam um sentido semântico enquanto sujeitos às condições de verdade, na medida em que afirmam a validade de uma norma. A validez é, nesse sentido, uma preocupação metalinguística. Os enunciados científicos, apesar de conterem informações sobre o campo temático a que se

\footnotetext{
${ }^{6}$ Tércio Sampaio Ferraz Jr. Teoria da norma jurídica, Rio de Janeiro, Forense, 1978, p. 141; Maria Helena Diniz, As lacunas, São Paulo, Saraiva, 2009, p. 21 a 24; Engisch, Introdução ao pensamento jurídico, Lisboa, Calouste Gulbenkian, 1964, prefácio do tradutor, p. XXVII; José Hermano Saraiva, Para uma visão coerente, $R B F$, fasc. 91, p. 245.

${ }^{7}$ Luís Alberto Warat, O direito e sua linguagem, Santa Catarina, 1983, p. 33, 36 37, 39 e 48; Juan-Ramon Capella, El derecho como lenguage, Barcelona, Ariel, 1968, p. 33,
} 
referem, evitando contradições, têm natureza criptonormativa, por conterem critérios para as decisões jurídicas, possibilitando a aplicação do direito. ${ }^{8}$

$\mathrm{O}$ discurso, ou melhor, a linguagem do jurista preenche as exigências da fundamentação racional, pois ele procura provar o que diz, ao sistematizar; atendendo as seguintes exigências: intenção de verdade, referência à realidade e conteúdo informativo.

Na ciência jurídica ter-se-á a atividade do jurista, que, após suas investigações, expõe suas conclusões numa sequência de enunciados, isto é, de proposições descritivas, que forma o contexto científico. No concreto exercício de redação de um texto científico-jurídico, a linguagem do jurista apresenta dois níveis: a) o da particularidade do texto, que vem do fato de ser de determinado autor, que possui seu estilo redacional, de virescrito em tal língua, de estar ligado a certa intenção do autor, de ter sido redigido em determinada situação e de destinar-se a um certo público; b) o da sistematicidade, que toma forma mediante um discurso condicionado, a uma corrente jusfilosófica, assentado sobre a articulação dos termos entre si, em sua estrutura sintática e semântica, tendo em vista a pretensão de verdade situada no âmbito das proposições descritivas.

A metalinguagem seria um instrumento para atingir a sistematicidade de um texto científico-jurídico, extraindo a parte de verdade que nele se presume, estudando-o não apenas com os instrumentos linguísticos e lógicos, mas também procurando abrir caminho para sua compreensão. Para que uma metalinguagem possa servir de instrumento para o método da compreensão do texto científico, tornando-se um auxiliar imprescindível para a leitura eficiente dos textos científico-jurídicos, deverá: a) apresentar uma definição clara de todos os termos utilizados; b) manter-se dentro dos limites da simplicidade e economia, no que se refere aos termos e à estrutura contextual; c) não mostrar contradições e d) ser consequente e metódico. ${ }^{9}$

A ciência jurídica preocupa-se com a exegese das normas, além de, conforme mundividência adotada, analisar outros elementos do direito, apenas como um instrumento capaz de obter enunciados tecnológicos ou científicos indicadores de critérios normativos para solucionar lacunas (integração) e antinomias (correção), ou até mesmo de critérios lógicos que poderiam orientar a interpretação na subsunção, pois sua finalidade é dar uma orientação para o aplicador do direito. ${ }^{10}$

A ciência jurídica busca fixar os limites da aplicação jurídica, visto que compete apresentar o direito como um todo coerente, contendo uma unidade sistemática, numa tentativa de conciliar contradições, sem contudo eliminá-las, apontar critérios para a integração de lacunas e correção de antinomias reais e para a interpretação das normas, criando condições para apresentar soluções, dando respostas aptas para que seja possível uma decisão daqueles problemas hermenêuticos com um mínimo de perturbação social. ${ }^{11}$

\footnotetext{
${ }^{8}$ Villanova, Lourival, Logica in Filosofia II-Anaias do VIII Congresso Interamericano de Filosofia e V da Sociedade Interamericana de Filosofia, p. 535 a 541, 550 a 552

9 Consulte: Newton Carneiro Affonso da Costa, Sobre a teoria lógica da linguagem, $R B F, 29: 68$; Ladrière, Langage scientifique et langage spéculative, Revue Philosophique de Louvain, n. 1 e 2, p. 131 e seguintes (1971). Ernildo Stein, Metalinguagem, in Filosofia-I, Anais do VIII Congresso Interamericano de Filosofia e V da Sociedade Interamericana de Filsofia, p. 293-307.

${ }^{10}$ Carlos Coelho Miranda Freire, Influencias da doutrina jurídica nas decisões judiciárias, João Pessoa, Ed. União, 1977, p. 99 e 5; Engisch, Introdução ao pensamento jurídico, cit. Cap. IV; Tércio Sampaio Ferraz Jr., A ciência do direito, cit. p. 82-103.

${ }^{11}$ Tércio Sampaio Ferraz Jr. Função social, cit. p. 177 a 194.
} 
Os enunciados científicos estão a serviço da realizabilidade da aplicação do direito ${ }^{12}$. E o sistema é o resultado da atividade do jurista idôneo para conduzir à solução de problemas interpretativos, integrativos e corretivos.

Àguisa de conclusão, poder-se-ia dizer que a ciência jurídica envolve uma atividade intelectual dirigida à aquisição do conhecimento do direito, sendo, por tal razão, um conjunto ordenado de processos mentais e de demonstrações. A ciência do direito indica qualquer estudo metódico, sistemático e fundamentado dirigido à aplicação do direito, pois procura apresentar soluções viáveis para os possíveis problemas. E a sistematização corresponde ao momento culminante em que o jurista terá as conclusões necessárias, coordenando-as, tendo em vista as condições de aplicabilidade da norma ${ }^{13}$. Daí ser a sistematização o problema fundamental do jurista.

\section{BIBLIOGRAFIA}

ALVES DA SILVA, Introdução à ciência do direito, São Paulo, Salesianas, 1940.

CAPELLA, Juán Ramon, El derecho como lenguage, Barcelona, Ariel, 1968.

COSTA, Newton C. A da. Sobre a teoria lógica da linguagem, RBF, 29:68.

DINIZ, Maria Helena. As lacunas no direito. São Paulo, Saraiva, 2009.

ENGISCH, Introdução ao pensamento jurídico, Lisboa, Calouste Gulbenkian, 1964.

FERRAZ JR, Tércio, A ciência do direito, São Paulo, Atlas, 1977; Direito, retórica e comunicação, São Paulo, Saraiva, 1973; Função social da dogmática jurídica, São Paulo, Revista dos Tribunais, 1978; Sistema jurídico e teoria geral dos sistemas, apostila do curso de extensão universitária em direito promovido pela AASP, Março a junho de 1973; Teoria da norma jurídica, Rio de Janeiro, Forense, 1978.

GILLES, Pensée formelle et sciences de l'homme, 1967.

LARENZ, Metodologia de la ciencea del derecho, Barcelona, Ariel, 1966.

MARTINS, José S. O método no direito, Revista da Faculdade de Porto Alegre, n. 1, 1951.

MIRANDA FREIRE, Carlos Coelho, Influência da doutrina jurídica nas decisões judiciárias, João Pessoa, ed. União, 1977.

MORENO, Júlio Luis. Los supuestos filosóficos de la ciencia jurídica, Montevideo, 1963.

MOUCHET, Carlos e BECU, Ricardo Z. Introducción al derecho, Buenos Aires, AbeledoPerrot, 1970.

REALE, Miguel, Lições Preliminares de direito, São Paulo, Saraiva, 1975.

SARAIVA, José h. Para uma visão coerente, $R B F$ n. 91.

\footnotetext{
${ }^{12}$ Larenz, Metodologia de la ciencia del derecho, Barcelna, Ariel, 1966, p. 19 e s.

${ }^{13}$ Reale, Miguel, Lições Preliminares de direito, São Paulo, Saraiva, 1975, p. 318 a 321.
} 
STEIN, Ernildo, Metalinguagem, in Filosofia-I, Anais do VIII Congresso Interamericano de Filosofia e V da Sociedade Interamericana de Filosofia.

VILLANOVA, Lourival, Logica in Filosofia II-Anaias do VIII Congresso Interamericanode Filosofia e V da Sociedade Interamericana de Filosofia.

WARAT, Luís Alberto, O direito e sua linguagem, Santa Catarina, 1983. 